\title{
Public health response to a large-scale endoscopy infection control lapse in a nonhospital clinic
}

\author{
Jacqueline Willmore $\mathrm{MPH}^{1}$, Edward Ellis $\mathrm{MD} \mathrm{MPH}^{2,3}$, Vera Etches MD MHSc ${ }^{1,3}$, Lise Labrecque MHSc BSW ${ }^{1}$, \\ Carla Osiowy $\mathrm{PhD}^{4,5}$, Anton Andonov MD PhD ${ }^{4,5}$, Cameron McDermaid MHSc ${ }^{1}$, Anna Majury DVM PhD 6,7 , \\ Camille Achonu MHSc${ }^{8}$, Maurica Maher MD ${ }^{9}$, Brenda MacLean RN BScN MEd ${ }^{1}$, Isra Levy MD MSc ${ }^{1}$
}

\begin{abstract}
J Willmore, E Ellis, V Etches, et al. Public health response to a large-scale endoscopy infection control lapse in a nonhospital clinic. Can J Infect Dis Med Microbiol 2015;26(2):77-84.

OBJECTIVE: To determine whether transmission of blood-borne pathogens (BBPs) (hepatitis B virus [HBV], hepatitis $\mathrm{C}$ virus $[\mathrm{HCV}]$ and HIV) occurred as a result of endoscopy reprocessing failures identified during an inspection of a nonhospital endoscopy clinic in 2011. METHODS: The present analysis was a retrospective cohort study. Registered notification letters were mailed to 6992 patients who underwent endoscopy from 2002 to 2011 at one Canadian nonhospital endoscopy clinic, informing them of the infection control lapse and offering BBP testing. Multimedia communications and a telephone line supplemented notification. A retrospective study of patients with BBPs was performed with viral genetic testing and risk factor assessment for eligible patients. Risk for infection among patients whose procedure was within seven days of a known positive patient was compared with those whose procedure was performed more than seven days after a known postive patient. The seven-day period was selected as the period most likely to present a risk for transmission based on the documented cleaning procedures at the clinic and the available literature on virus survival.

RESULTS: Ninety-five percent (6628 of 6992) of patients/estates were contacted and 5042 of 6728 (75\%) living patients completed BBP testing. Three were newly diagnosed with HBV and 14 with HCV. Twentythree and 48 tested positive for previously known HBV or HCV, respectively, 367 were immune to $\mathrm{HBV}$ due to natural infection and one was immune to HBV due to immunization. None tested positive for HIV. Sequencing did not reveal any relationships among the 46 unique case patients with viral genetic test results available. Ninety-three percent of patients reported alternative risk factors for BBP. An increased risk for infection among those who underwent a procedure within seven days of a known HBV or HCV case was not demonstrated.

CONCLUSIONS: Endoscopy reprocessing failures were not associated with an increased risk for BBP among individuals tested.
\end{abstract}

Key Words: Endoscopy; Infection control lapse; Public health

\section{La réaction de la santé publique à une vaste défaillance du contrôle des infections en endoscopie dans une clinique non hospitalière}

OBJECTIF : Lors de l'inspection d'une clinique d'endoscopie non hospitalière en 2011, déterminer si des pathogènes à diffusion hématogène (PDH; virus de l'hépatite B [VHB], virus de l'hépatite C [VHC] et VIH) sont transmis à cause de la défaillance du retraitement de l'endoscopie. MÉTHODOLOGIE : Dans la présente étude de cohorte rétrospective, les chercheurs ont posté une lettre recommandée à 6992 patients qui avaient subi une endoscopie entre 2002 et 2011 dans une clinique canadienne d'endoscopie non hospitalière pour les informer d'une défaillance du contrôle des infections et leur offrir un test de dépistage des PDH. Les communications multimédias et les appels téléphoniques ont complété cet avis. Les chercheurs ont effectué une étude rétrospective des patients ayant des $\mathrm{PDH}$ au moyen de tests génétiques viraux et d'une évaluation des facteurs de risque des patients admissibles. Ils ont comparé le risque d'infection entre les patients dont l'intervention avait eu lieu dans les sept jours suivant celle d'un patient positif connu ceux dont l'intervalle dépassait sept jours. Cette période de sept jours était la plus susceptible de constituer un risque de transmission compte tenu des mesures de nettoyage attestées à la clinique et les publications sur la survie des virus.

RÉSULTATS : Les chercheurs ont pris contact avec $95 \%$ (6 628 cas sur 6692 ) des patients et des successions, et 5042 des 6728 (75\%) patients vivants ont effectué le test de dépistage des PDH. Trois ont obtenu un nouveau diagnostic de VHB et 14, de VHC. De plus, 23 et 48 ont obtenu des résultats positifs à un $\mathrm{VHB}$ ou à un $\mathrm{VHC}$ déjà connu, respectivement, 367 étaient immuns au VHB en raison d'une infection naturelle et un, grâce à la vaccination. Aucun n'a obtenu de résultat positif au VIH. Le séquençage a révélé l'absence de lien entre les 46 cas uniques de patients pour qui les résultats du test génétique étaient disponibles. Aussi, $93 \%$ des patients ont signalé d'autres facteurs de risques de PDH. Par ailleurs, on n'a pu démontrer d'augmentation du risque d'infection chez les personnes qui avaient subi une intervention dans les sept jours suivant un cas connu de VHB ou de VHC.

CONCLUSIONS : L'échec de retraitement de l'endoscopie ne s'associait pas à une augmentation du risque de PDH chez les personnes qui subissaient un test de dépistage.

been reported to be one case per 1.8 million (4). This may underestimate incidence due to a lack of postprocedure surveillance and underreporting. Despite the low estimated incidence of infection, several large-scale endoscopy-related outbreaks and notifications have been reported in the literature $(5,6)$. Few have established transmission of blood-borne pathogens (BBP), such as hepatitis B virus (HBV), hepatitis $\mathrm{C}$ virus (HCV) and HIV, as a result of reprocessing errors (7-9). However, $\mathrm{HBV}$ and $\mathrm{HCV}$ can survive on inanimate surfaces for several
$\mathrm{M}$ ore than 1.6 million endoscopic procedures are performed annually in Canada (1). The increasing proportion of colonoscopies and other medical procedures being performed in nonhospital (NH) clinics (2) prompted the College of Physicians and Surgeons of Ontario (CPSO) to launch the Out-of-Hospital Premises Inspection Program in 2010 (3). Before this program was implemented, NH facilities performing procedures such as endoscopies were not inspected. The incidence of infections (primarily bacterial) associated with endoscopy has
${ }^{1}$ Ottawa Public Health; ${ }^{2}$ Public Health and Preventive Medicine Consultant; ${ }^{3}$ University of Ottawa, Ottawa, Ontario; ${ }^{4}$ National Microbiology
Laboratory, Public Health Agency of Canada; ${ }^{5}$ University of Manitoba, Winnipeg, Manitoba; ${ }^{6}$ Public Health Ontario; ${ }^{7}$ Queen's University,

Kingston; ${ }^{8}$ Public Health Ontario, Toronto; ${ }^{9}$ Health Canada, Ottawa, Ontario

Correspondence: Jacqueline Willmore, Ottawa Public Health, 100 Constellation Crescent, 7th Floor West, MC: 26-50, Ottawa, Ontario

K2G 6J8. Telephone 613-853-3876, fax 613-580-9601, e-mail jacqueline.willmore@ottawa.ca
OPEN $\bigcirc$ ACCESS

This open-access article is distributed under the terms of the Creative Commons Attribution Non-Commercial License (CC BY-NC) (http:// creativecommons.org/licenses/by-nc/4.0/), which permits reuse, distribution and reproduction of the article, provided that the original work is properly cited and the reuse is restricted to noncommercial purposes. For commercial reuse, contact support@pulsus.com 
days depending on conditions (10-14) and infections may go undetected for long periods of time, with serious health consequences (15).

In May 2011, an NH endoscopy clinic in Ottawa, Ontario, was inspected by the CPSO and significant deficiencies in the cleaning and disinfection of the endoscopes since 2002 were identified. Specifically, the inspection found cross-contamination from a dirty endoscope, inadequate decontamination of biopsy forceps, improper use of endoscope processor for high-level disinfection of endoscopes and sterilization of instruments such as biopsy forceps, and no proper cleaning of premises between patients (16). CPSO ordered the clinic physician to cease performing endoscopies at the clinic and notified the Ontario Ministry of Health and Long-Term Care (MOHLTC) about the issue. The MOHLTC notified Ottawa Public Health (OPH), the local public health department. The main objectives of $\mathrm{OPH}$ were to assess the risk of transmission of HBV, HCV and HIV to patients and to determine whether a public health response was needed.

\section{METHODS}

A decision to notify patients was made by OPH based on assessments of infection risk and ethics considerations, and in consultation with experts in these areas. Due to the large number of affected patients, the clinic could not independently undertake notification and follow-up. An epidemiological investigation, including genetic analysis, was designed to assess whether there was evidence of patient-to-patient transmission of BBP.

\section{Infection risk}

The risk for infection with HBV, HCV and HIV was estimated using prevalence estimates (17-19) and the Rutala and Weber methodology $(20,21)$ recommended by the Public Health Agency of Canada. This methodology includes a 14-step protocol for situation management in the event of a possible failure of disinfection or sterilization that could expose patients to an infectious agent. It includes situational evaluation, stakeholder communication, risk evaluation and investigation (20). The risk for infection was estimated to be $<1$ in 1 million patients for $\mathrm{HBV},<1$ in 50 million patients for $\mathrm{HCV}$ and $<1$ in 3 billion patients for HIV (22). This process is described in more detail in Appendix 1.

\section{Ethics considerations}

Clinical and public health ethics principles and values were considered in deciding whether patient notification was indicated (22). Principles of patient autonomy, the right to know and the professional duty to disclose led to a conclusion that disclosure by the physician and/or public health officials was warranted $(23,24)$. Public health principles of do no harm (nonmaleficence) (25) and protection of the public from harm (26) also supported disclosure, due to the possibility of secondary transmission of BBP to others by infected patients unaware of their infection.

The potential harm of patient distress and anxiety about potential infection with a BBP (however small the risk) that could arise with disclosure was considered (27). However, disclosure is ethical even when the chance of harm is extremely low, although steps must be taken to minimize patient anxiety. Following the principle of transparency, disclosing risk information to patients was determined to be an ethical course of action that would maintain public trust in $\mathrm{OPH}(23,28)$.

\section{Patient identification and notification}

A 'confirmed patient' underwent an endoscopic procedure in the clinic between April 1, 2002 and June 1, 2011, based on Ontario Health Insurance Plan (OHIP) billing records, clinic records for patients not billed through OHIP, or a plausible history from a selfidentified patient lacking billing and clinic records. OPH compiled and managed all patient information related to the response in a secure Microsoft Access database (Microsoft Corporation, USA).

A package was sent by registered mail or personal delivery (to allow for tracking of package receipt or return) to each patient including a letter signed by the Ottawa Medical Officer of Health and the clinic physician. The letter described the infection control lapse (ICL), stated the estimated numeric risk of BBP infection, offered testing (but did not specifically recommend testing), provided instructions for obtaining free laboratory testing using a prepopulated Public Health Ontario Laboratory requisition (to improve access and facilitate surveillance), conveyed the clinic physician's regret for the incident, and provided a dedicated OPH telephone number and website for further information. Telephone metrics were tracked through Prairie Fyre, a contact management software, and patient satisfaction data were logged electronically by nursing staff who managed the telephones. Local family physicians, infectious disease specialists, gastroenterologists and emergentologists were also notified. Traditional and social media were used to inform patients who could not be reached through postal mail.

\section{Case identification}

A 'case patient' had laboratory evidence of an acute, chronic, occult or past HBV infection, an HCV infection or an HIV infection, based on current test results or previously known test results in Ontario's reportable disease database. All assays were performed using a chemiluminescent microparticle immunoassay (Architect i2000SR, Abbott Diagnostics, USA). Assays included qualitative detection of antibody to hepatitis B surface antigen (anti-HBsAg), hepatitis B surface antigen ( $\mathrm{HBs} \mathrm{Ag}$ ), antibody to hepatitis $\mathrm{B}$ core antigen (anti-HBcAg), antibody to HCV (anti-HCV) and HIV p24 antigen and antibodies to HIV type 1 and/or type 2 (HIV-1/HIV-2). Patients acutely or chronically infected with HBV (HBsAg positive), or with evidence of previous or occult infection (HBsAg negative, anti-HBc positive, and anti-HBs $\leq 100 \mathrm{mIU} / \mathrm{mL}$ ) were classified as HBV cases. Patients were considered to be immune due to immunization if they were anti$\mathrm{HBsAg}$ positive, $\mathrm{HBs} \mathrm{Ag}$ negative and $\mathrm{HBc}$ negative. Patients with positive anti-HCV were classified as $\mathrm{HCV}$ cases. HIV-seropositive patients were classified as HIV cases. All samples that tested positive using the initial chemiluminescent microparticle immunoassay were subject to confirmatory testing.

\section{HBV DNA and HCV RNA testing and sequencing}

Patients with HBsAg-positive serum samples and those that were potentially occult cases of HBV infection (in the present study, $\mathrm{HBs} A g$ negative, anti-HBc positive, and anti-HBs $\leq 100 \mathrm{mIU} / \mathrm{mL}$ ) were eligible for HBV DNA testing and eligible samples were sent to the National Microbiology Laboratory, Public Health Agency of Canada for blinded HBV DNA testing. Anti-HCV serology positive patients who had not demonstrated undetectable HCV RNA previously were eligible for HCV RNA testing. Samples were sent to the National Microbiology Laboratory for blinded HCV RNA testing. If nested polymerase chain reactions (PCRs) determined viral nucleic acid positivity (detection limit between $5 \mathrm{IU} / \mathrm{mL}$ to $10 \mathrm{IU} / \mathrm{mL}$ ) in serum samples, HBV DNA and HCV RNA extracted from clinical samples were genotyped and sequenced to assess phylogenetic relatedness of viral samples collected from case patients.

HBV DNA was extracted from $200 \mu \mathrm{L}$ of sera using silica gel filtration (easyMAG, bioMérieux, Canada) or phenol/chloroform extraction methods to optimize sensitivity (29). Extracted DNA was amplified according to previously published procedures $(30,31)$. Samples that could be amplified by at least two different region-specific primer sets and were $\mathrm{HBsAg}$ negative, anti-HBc positive and anti-HBs $\leq 100 \mathrm{mIU} / \mathrm{mL}$ were considered to be occult HBV infection positive (32). A total of 315 base pairs, consistent across all patients, were queried during phylogenetic analysis. The gene sequence evaluated for HBV was the surface/polymerase overlapping sequence. Sanger sequencing provided analysis of the dominant population within the patient quasispecies, which allowed for adequate tracing of transmission events.

HCV RNA was extracted from $250 \mu \mathrm{L}$ of sera using the automated nucleic acid extraction system NucliSENS easyMag (bioMérieux Inc, USA) and amplified, gel purified, then cycle sequenced with an ABI Prism 3100 Genetic Analyzer (Applied Biosystems, USA) using BigDye v3.1 terminator chemistry. Sequence data obtained were used to determine the HCV genotype of each viral sample and further analysis was 
performed to determine their phylogenetic relatedness. Genetic distances were estimated by Kimura two-parameter analysis, and a phylogenetic tree was constructed using the maximum likelihood method (33). Significant taxonomic relationships were identified by bootstrap resampling analysis (200 replicates) using the maximum likelihood method. Bootstrap values of $\geq 70 \%$ indicate that the topology of that branch within the phylogenetic tree were considered to be significant or 'related'.

\section{Prevalence, risk factor and OR analysis}

To determine whether there was a higher than expected prevalence of any BBP, the prevalence among those tested as a result of the notification was compared with the estimated prevalence in the population of Ottawa (HIV), Ontario (HCV) or Canada (HBV) (as available in the literature), using a Pearson's $\chi^{2}$ test at $\alpha=0.05(17-19)$.

Public health nurses conducted standardized telephone interviews of case patients regarding any previous test results, HBV immunization and lifetime exposure to recognized risk factors for acute infection $(34,35)$. If the case patient was unavailable and a previous interview record existed, information was abstracted from the provincial reportable disease database. Risk factor responses were collated into mutually exclusive risk factor categories using a previously published hierarchy $(35,36)$.

Odds of infection were calculated using Stata version 12.0 (StataCorp, USA). In this analysis, a case was any confirmed patient who was HBV positive and for whom the HBV status was not known to be positive before their procedure. A control was any confirmed patient who tested negative for HBV. A case or control was considered exposed if they had a clinic visit within seven days after the visit of a known case patient. For the attribution of exposures, confirmed patients who were known to be positive before their endoscopy date were included as transmission exposures: they could act as a source of infection. These confirmed patients were excluded from the analysis because they did not meet case or control definitions. Patients whose laboratory tests indicated they were immune due to immunization were excluded if the vaccination was definitively before their endoscopy procedure. Because some patients had multiple visits, each visit was considered to be an independent case or control visit and the risk analysis was performed on 'patient-visits' rather than individual patients.

The seven-day duration for temporal linking was selected by considering the extent to which endoscope cleaning occurred according to clinic records, although insufficient according to the guidelines (37), and evidence of virus survival in the literature (10-14). Given that HBV and HCV can go undetected for long periods of time (15), all case patients were assumed to be infectious at the time of their clinic visit(s), to consider their infection and transmission risk. Although the seven-day period was believed to present the highest risk to patients, additional exposure periods of 14 days and 28 days were also used as a sensitivity analysis.

\section{Notification results}

\section{RESULTS}

The notification process resulted in 95\% (6628 of 6992) of confirmed patients or estates receiving a package by registered mail or delivery (Table 1). More packages were mailed than confirmed patients due to address changes, and lost or returned packages.

\section{Viral test results}

Of 6728 confirmed living patients (96\% of 6992 confirmed patients or estates of confirmed patients), 5042 (75\%) completed viral testing for at least one BBP as of May 11, 2012. Among living patients, 62\% (4173 of 6728) were female and the median age (as of January 1, 2011) was 55.2 years (range 15 to 99 years), older than the 2011 Ontario median age of 40.4 (38). Data regarding sex were missing in 319 cases $(4.7 \%)$ and age in $171(2.5 \%)$. There were 442 ( $8.8 \%$ of 5042$)$ case patients identified who tested positive for a past or current infection with $\mathrm{HBV}$ or $\mathrm{HCV}$, including 12 coinfections (Figure 1). No HIV cases were identified. One

\section{TABLE 1}

Patient notification results, as of April 2012

\begin{tabular}{lcc}
\hline Notification process & $\mathbf{n ~ ( \% )}$ & Total, $\mathbf{~}$ \\
\hline Confirmed patients identified & 6992 & \\
Patients confirmed alive at time of notification & $6728(96.2)$ & 6992 \\
Packages sent to patients and estates & 7310 & \\
Patients or estates reached by registered mail & $6628(94.8)$ & 6992 \\
Patients who received testing for at least one BBP & $5042(74.9)$ & 6728 \\
Patients tested for HIV & $5042(74.9)$ & 6728 \\
Patients tested for HBV & $4703(69.9)$ & 6728 \\
Patients tested for HCV & $4730(70.3)$ & 6728 \\
Stakeholders notified (eg, physicians, & 1400 &
\end{tabular}

laboratories, hospitals, public health units)

Calls received by $\mathrm{OPH}$ from patients, members of the public

Calls made by OPH nurses notifying patients of negative laboratory results

Calls received by $\mathrm{OPH}$ from physicians/other health care providers

Patients reached by letter to inform them of option for genetic sequencing

BBP Blood-borne pathogen; HBV Hepatitis B virus; HCV Hepatitis $C$ virus $\mathrm{OPH}$ Ottawa Public Health

case demonstrated immunity to $\mathrm{HBV}$ due to vaccination. Forty-eight of $62 \mathrm{HCV}$ cases $(77.4 \%)$ and 23 of 26 of those with current HBV infection $(88.5 \%)$ were known from Ontario's reportable disease database. Fifty-six percent (247 of 442) of case patients were female, and the median age was 58.2 years (range 24 to 90 years). Results of initial viral testing in the patients tested as a part of the epidemiological investigation were compared with available general population prevalence estimates for HIV (Ottawa estimate), HCV (Ontario estimate) or HBV (Canadian estimate) (17-19) using Pearson's $\chi^{2}$ test (Table 2). The prevalence of HBV and HIV was significantly lower than expected, past infection with $\mathrm{HBV}$ was within the expected range and the prevalence of $\mathrm{HCV}$ was not significantly different than expected.

Ninety-three percent (324 of 350) of HBV or HCV case patients who could be interviewed reported alternate risk factors to endoscopy at the clinic. Patients were assigned to the risk factor with the highest risk (Table 3). Decedents $(n=34)$ and patients who could not be reached and did not have a patient file available $(n=31)$ were excluded.

Statistical analysis did not detect increased odds of HBV or HCV infection among patients potentially exposed to a case patient (Table 4). One case was removed from the analysis because this case was definitively immune before their endoscopy. Sixty-three HBVpositive patients and $50 \mathrm{HCV}$-positive patients were removed from the risk analysis because they were known to be positive before their procedures. Fourteen- and 28-day periods were also used as periods of exposure, and neither detected increased odds of HBV or HCV infection among exposed patients.

\section{HBV DNA test results}

Of HBV cases, 182 were eligible for and were offered DNA testing. A total of $130 \mathrm{HBV}$ DNA tests were performed on $18 \mathrm{HBsAg}$ positive specimens, $88 \mathrm{HBs} A$-negative specimens and 24 specimens in which the HBsAg status was not provided. Twenty specimens were DNA positive according to PCR. Five HBsAg-negative, anti-HBcpositive and anti-HBs-positive $(\leq 100 \mathrm{mIU} / \mathrm{mL})$ specimens, and one specimen in which the HBsAg status was not provided, were considered to be PCR indeterminate because the initial positive PCR result could not be replicated with different primer sets. The 26 sequences were phylogenetically analysed. Three specimens were considered to be occult HBV infection positive (HBsAg negative and PCR positive in different genomic regions). Transmission of HBV related to endoscopy procedures at the clinic was unlikely, as 
TABLE 2

Seroprevalence of hepatitis B virus, hepatitis C virus (HCV) and HIV infection for all patients tested as a part of the endoscopy epidemiological investigation

\begin{tabular}{|c|c|c|c|c|c|}
\hline Infection & Patients tested, $\mathbf{n}$ & $\begin{array}{c}\text { Expected prevalence*, } \\
\% \text { ( } \mathrm{n} \text { expected) }\end{array}$ & $\begin{array}{c}\text { Observed prevalence, } \\
\mathbf{n}(\%)\end{array}$ & $\begin{array}{c}\text { Interpretation } \\
\left.\text { (Pearson's } \mathrm{X}^{2} \mathrm{P}\right)\end{array}$ & $\begin{array}{c}\text { Comparison } \\
\text { population }\end{array}$ \\
\hline HBsAg positive & 4703 & $2(94)$ & $26(0.55)$ & Lower $(P<0.001)$ & Canada \\
\hline Anti-HBc positive (past infection) & 4703 & $5-10(235-470)$ & $366(7.8)$ & Within range (NA) & Canada \\
\hline HCV antibody positive & 4730 & $0.94(44)$ & $62(1.3)$ & Not different $(P=0.08)$ & Ontario \\
\hline HIV antibody positive & 5042 & $0.37(19)$ & $0(0)$ & Lower $(P<0.001)$ & Ottawa \\
\hline
\end{tabular}

${ }^{*}$ Data adapted from references 17-19. Anti-HBc Hepatitis B core antibody; HBcAg Hepatitis B core antigen; HBsAg Hepatitis B surface antigen; NA Not applicable

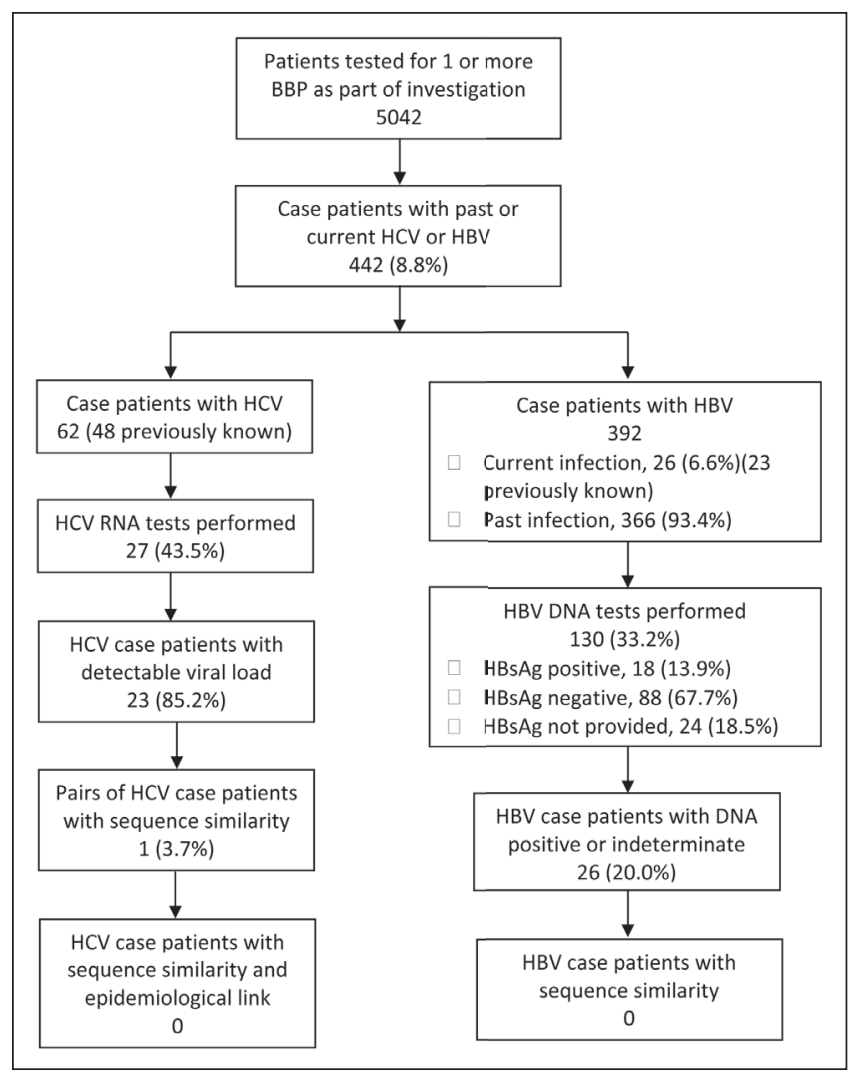

Figure 1) Flow diagram depicting results of testing for hepatitis $B$ virus (HBV) and hepatitis $\mathrm{C}$ virus (HCV) among patients tested as part of the epidemiological investigation in Ottawa, Ontario. BBP Blood-borne pathogen; HBsAg Hepatitis B surface antigen

indicated by insufficient sequence similarity based on genotype and placement on the tree (Figure 2C).

HCV RNA test results

Samples from 27 of 55 eligible anti-HCV-positive patients were tested for HCV RNA; of these, 23 were positive with a viral load ranging from $3.57 \times 10^{4} \mathrm{IU} / \mathrm{mL}$ to $2.46 \times 10^{7} \mathrm{IU} / \mathrm{mL}$. Samples from all $23 \mathrm{HCV}$ RNA positive patients were genotyped; subgenotype 1a was the most common (10 cases) followed by subgenotype $1 \mathrm{~b}$ (six cases). Three cases belonged to subgenotype 3 a, three to genotype 4 and one to subgenotype 2a (Figure 2A). One of the three genotype 4 cases belonged to subgenotype $4 \mathrm{a}$, commonly found in Egypt, while the other two were the rarely observed subgenotypes $4 \mathrm{v}$ and $4 \mathrm{r}$. A possible transmission event could have occurred only within cases belonging to the same subgenotype.

Analysis of all 1a and 3a cases did not identify clusters of phylogenetically related HCV strains among these patients except for samples H0296/12 and H0501/12; however, these were duplicate samples from the same patient (the laboratory tested all samples in a blind
TABLE 3

Hierarchical, mutually exclusive risk factors* for hepatitis B virus (HBV) or hepatitis C virus (HCV) among interviewed acute cases, chronic carriers and those with evidence of past infection, as of April 2012

\begin{tabular}{lcc}
\hline & HBV & HCV \\
\cline { 2 - 3 } Risk factor & Total $\mathbf{n}=\mathbf{3 5 0 ^ { \dagger }}$ & Total $\mathbf{n}=\mathbf{2 7} \mathbf{f}^{\dagger}$ \\
\hline Injection drug use & $2(0.6)$ & $10(37.0)$ \\
Non-injection drug use & $3(0.9)$ & $1(3.7)$ \\
Transfusion $^{\ddagger}$ & $20(5.7)$ & $2(7.4)$ \\
$>$ 2 heterosexual partners & $78(22.3)$ & $2(7.4)$ \\
Men who have sex with men & $8(2.3)$ & $0(0)$ \\
Sex with carrier & $7(2.0)$ & $0(0)$ \\
Tattooing & $7(2.0)$ & $2(7.4)$ \\
Body piercing & $64(18.3)$ & $6(22.2)$ \\
Acupuncture & $24(6.9)$ & $1(3.7)$ \\
Occupational & $19(5.4)$ & $1(3.7)$ \\
HBV/HCV in home & $6(1.7)$ & $0(0)$ \\
Surgery or invasive procedure other & $25(7.1)$ & $0(0)$ \\
than the endoscopy clinic & & \\
Incarceration & $1(0.3)$ & $0(0)$ \\
Born in a high-prevalence country & $60(17.1)$ & $0(0)$ \\
No disclosed risk & $26(7.4)$ & $2(7.4)$ \\
\hline
\end{tabular}

Data presented as $n$ (\%). ${ }^{*}$ Data adapted from references 35 and 36 . ${ }^{\dagger}$ Decedents $(n=34)$ and patients who could not be reached and did not have a patient file available $(n=31)$ were excluded. $¥$ Only transfusions outside Canada anytime (for both HBV and HCV), or transfusions pre-1970 (for HBV) or pre1990 (for HCV) were included

\section{TABLE 4}

Risk analysis of exposure from a clinic visit within seven days of a case patient's visit, as of August 2012*

\begin{tabular}{lcccc}
\hline HBV & Positive & Negative & OR & $\mathbf{9 5 \% ~ C l}$ \\
\hline Exposed & 340 & 3893 & 1.03 & $(0.84-1.29)$ \\
Not exposed & 98 & 1166 & & \\
HCV & Positive & Negative & OR & $\mathbf{9 5 \% ~ C l}$ \\
\hline Exposed & 8 & 1369 & 0.87 & $(0.40-1.87)$ \\
Not exposed & 28 & 4148 & & \\
\hline
\end{tabular}

${ }^{*}$ Based on clinic visits because patients could have multiple visits. Excludes patients who were known to be positive before their endoscopy visit. HBV Hepatitis B virus; HCV Hepatitis $C$ virus

manner). Similarly from the six subgenotype $1 \mathrm{~b}$ cases, sample pairs H0295/12-H0500/12 and H1284/12-H5899/11 carried identical HCV sequences; however, they were also found to be duplicate specimens from the same patients. Interestingly, these two HCV strains were phylogenetically associated (bootstrap value $=87 \%$ ); however, the epidemiological data did not confirm possible transmission because the visits of these two patients were one year apart. To further investigate the discrepancy between the phylogenetic and epidemiological data, these two HCV strains were analyzed within the NS5B region 


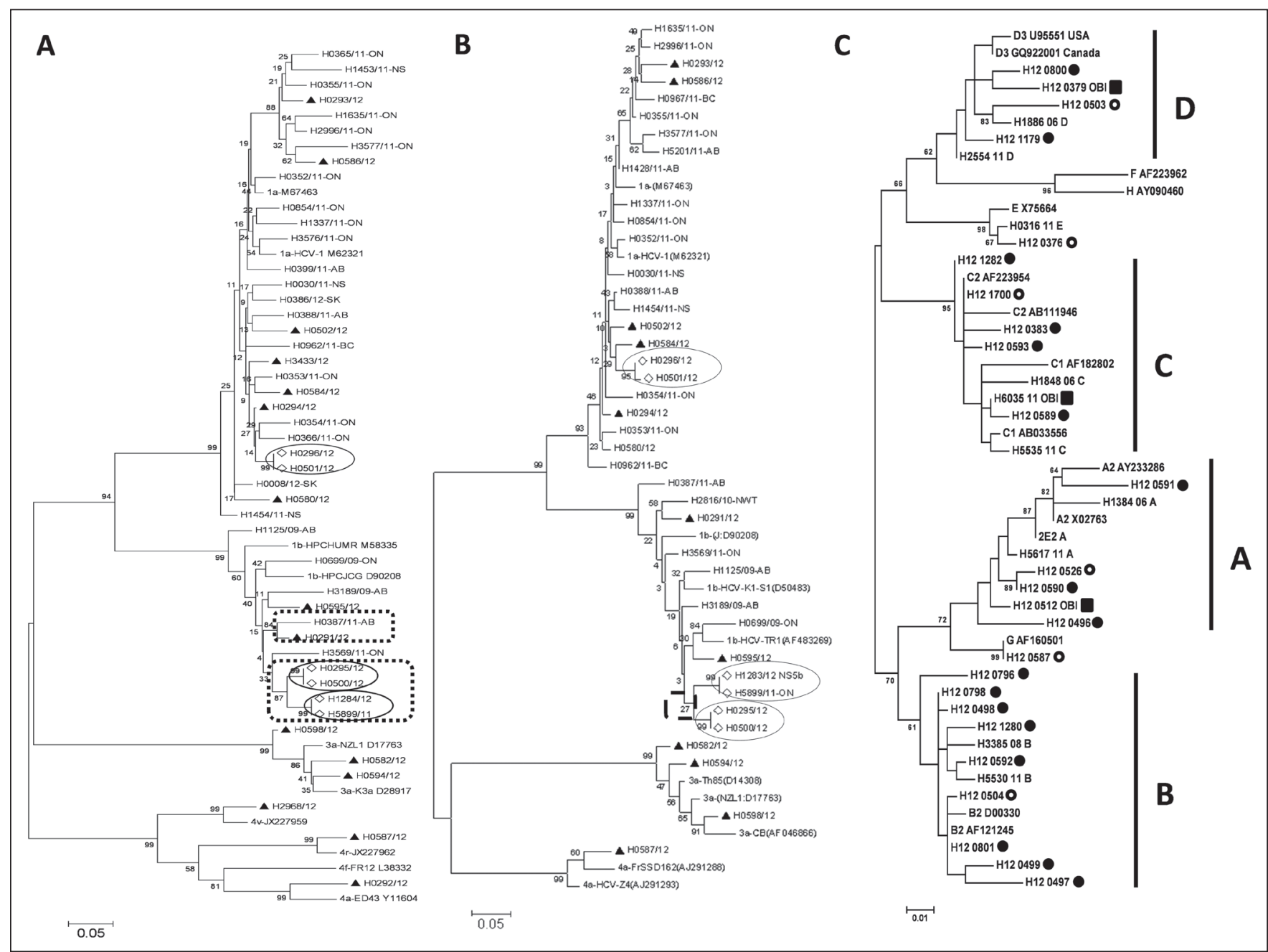

Figure 2) Results of phylogenetic analysis of hepatitis $\mathrm{C}$ virus (A and B) and hepatitis B virus (HBV) (C). A Phylogenetic tree based on partial hepatitis $\mathrm{C}$ virus E1 genetic region; samples from the Ottawa (Ontario) clinic patients are marked with black triangles. Regional reference clinical cases from Alberta (AB), British Columbia (BC), Ontario (ON) and Saskatchewan (SK), as well as GenBank sequences belonging to different subgenotypes are included for comparison. Investigation cases with identical sequences are marked with open diamonds. Identical or almost identical sequences are encircled. Putative phylogenetic associations are marked with dashed rectangles. B Phylogenetic tree based on partial NS5B region: markings as in A. Note that the putative phylogenetic association based on partial E1 sequences is not confirmed in NS5B region (samples H1283/12 and 1284/12 belong to the same patient and were collected 10 days apart). C Phylogenetic tree of 26 hepatitis B surface antigen (HBsAg)-coding region sequences (315 base pairs; HBV nucleotides 468-782) from 17 HBsAgpositive and nine HBsAg-negative or nonprovided clinic patients. Maximum likelihood analysis was performed using MEGA 5 software and the tree constructed by the Nearest Neighbour Interchange algorithm with 1000 bootstrap replicates (33). Comparative GenBank sequences are designated by the HBV genotype or subgenotype, followed by the accession number. Regional reference and case sequences are designated by a code number preceded by the letter $H$. The $2 E 2$ A sequence within the genotype A clade denotes the sequence of the positive control used during all polymerase chain reactions (PCRs). Bootstrap confidence values of $\geq 60 \%$ are given. The ruler shows the branch length for a pairwise distance equal to 0.01 . Filled circle, HBsAg positive, PCR positive; Open circle, HBsAg negative, PCR indeterminate; Filled square, HBsAg negative, PCR positive

(Figure 2B) and no support for phylogenetic relatedness was found. These observations highlight the importance of using more than one genetic region for phylogenetic analysis.

\section{DISCUSSION}

The public health response to a large-scale ICL in an NH endoscopy clinic included a risk assessment and ethics analysis resulting in a decision to notify almost 7000 patients, and to conduct further epidemiological and genetic investigation of case patients. Our investigation found no evidence for an increased risk of BBP acquisition associated with the endoscopy reprocessing failure. Although three new cases of HBV and 14 new cases of HCV were identified, we did not find any related sequences with an epidemiological link among patients with viral genetic analysis results and most case patients identified alternative risk factors. Additionally, the prevalence of BBP in the patient population that went for testing was not clinically higher than expected, particularly given that the median age of the patient population was older than the Ontario population and the fact that some patients were undergoing endoscopic procedures because of their HBV or HCV infection. The odds of infection were not significantly higher for patients who underwent a procedure within seven days after a known HBV or HCV case. These data argue against viral transmission during the endoscopic procedure and confirm what others have found with respect to the extremely low risk of transmission of BBP through endoscopy reprocessing failures (7-9).

Successful contact with $95 \%$ of patients was within the range ( $84 \%$ to $99 \%$ ) achieved in similar notification processes in other jurisdictions $(7-9,15,39)$. Factors possibly contributing to the high connection rate included the multipronged communication strategy, as well as repeated attempts to contact patients who did not receive their packages. Patient satisfaction was high on timeliness of services delivered, information provided and staff knowledge, competence and courtesy; the dedicated 
telephone line was considered to be essential to this outcome and to minimizing patient anxiety. The collaboration between $\mathrm{OPH}$ and local, provincial and national laboratories resulted in follow-up of the $75 \%$ of patients who chose to get tested. The investigation took almost one year to complete, due to multiple factors including, but not limited to, the lengthy patient identification process, a higher volume of telephone calls from patients than expected, the high number of patients who chose to undergo testing, and the length of time to obtain and report sequential positive and negative results to patients and their physicians. Lack of a predesigned database to manage the large volume of data from various components of the investigation led to data quality and data management problems, which were solved over the course of the investigation.

Limitations to the investigation included the extended risk period (complicating patient follow-up and identification of relevant risk factors among case patients), incomplete clinic patient records, the lack of preprocedure BBP test results for most patients, and having to use general rather than age-specific population prevalence of the BBP to compare with the prevalence found among confirmed patients. Because $25 \%$ of patients were not tested, it is possible that associations between case status and exposure may have changed if the status of this group was known. Temporality of case status or viral load and a patient's endoscopy visit could not be determined, in part because negative results for previously known cases are not reported to OPH. Positive patients were considered to be capable of transmitting infection in the OR analysis. The assumption that all positive patients were infectious may influence our outcomes toward the null. Risk factor information was missing for $8 \%$ of case patients, and these may be patients at greater risk for transmitting infection. Misclassification of exposures or case status could also affect the results. Because not all eligible patients underwent DNA/ RNA testing, a relationship among cases may have been overlooked.

Knowledge gained from this response will be useful for infection control professionals, public health officials and clinicians planning for or managing a potential ICL or other adverse event. While the infection control risk assessment and ethical assessment pointed to the need for a public health response to disclose the ICL to patients, little guidance was available on the most appropriate methods to use. The notification letters to patients and physicians and the dedicated telephone line proved to be vital components of the response. However, we would not recommend the additional cost of registered mail for a patient whose address is likely reliable (such as their OHIP record). Traditional and social media should be used to capture patients who may have recently moved without notifying OHIP. Genetic analysis was essential to complement the epidemiological investigation once new BBP cases were identified.

Given that our findings support the extremely low quantitative risk of infection from an endoscopy-related ICL, unless clear evidence of transmission is found we recommend others follow the Centers for Disease Control and Prevention (Georgia, USA) guidelines for a Category B breach (40). This approach would use a qualitative description of the risk in patient and public communication, explicitly stating that due to the extremely low risk of having been infected, testing for the infections is not generally recommended, but would suggest that patients may call the dedicated telephone line with questions, or speak to their primary health care provider if they would like to discuss testing. Thus, a prepopulated laboratory requisition would not be needed in the package and staff time spent informing patients of negative results by telephone could be avoided. Public health staff would be notified of positive results for reportable BBP as per local protocol and epidemiological investigations of these cases should include questions regarding endoscopies. If new BBP cases among patients with epidemiological links are identified, genetic analyses of these cases and a recommendation for testing of others who share the link (eg, visit on the same day) may then be warranted.

In addition to regular inspections of $\mathrm{NH}$ clinics, requirements for reporting of regular training and retraining for $\mathrm{NH}$ staff involved in reprocessing could help to prevent future ICLs. A requirement to document which reusable scope or other instrument is used on which patient could assist in investigations. Because other ICLs had occurred elsewhere in the province, the MOHLTC convened a provincial Task Group on Community Infection Prevention and Control Lapses to make recommendations on how to reduce the number and scale of future lapses, and on consistent public health assessment and management in an ethical and cost-effective manner for ICLs that do occur (41).

ACKNOWLEDGEMENTS: The authors thank members of the Incident Management System and other staff at OPH who contributed to the ICL response, and Epidemiology and Laboratory Services at Public Health Ontario for assistance with laboratory processes and data management.

\section{APPENDIX 1}

\section{Estimates for risk of disease transmission}

An approach to assessing the risk of disease transmission when there is a failure to follow established infection control procedures has been published by Rutala and Weber (20), and this is the approach is recommended by the Public Health Agency of Canada (21). This method was used to conduct the risk of disease transmission of HIV, HBV and HCV. The following data elements were used to calculate the probability of disease transmission:

- Prevalence of infection (17-19);

- Risk of transmission - risk of transmission for endoscopy alone was calculated using the risk of transmission from mucosal exposure; for endoscopy with biopsy the risk of transmission from percutaneous exposure was used $(42,43)$;

- Likelihood that a nondisinfected instrument was used - various percentages were used to obtain a range of estimates (1\%, 10\%, $25 \%, 50 \%, 75 \%$ and $100 \%$ );

- Efficacy of cleaning using automated endoscope reprocessor (44);

- Efficacy of disinfection for liquid chemical sterilant (glutaraldehyde). Endoscope reprocessing involves five steps: precleaning with enzymatic detergent, leak testing, manual cleaning and rinsing, high level disinfection and rinsing, and drying and storing. Automated endoscope reprocessors can be used to perform several functions, but manual cleaning must always be performed before placing the endoscope in a reprocessor.

Data from the manufacturer of the reprocessor used at the facility states that exposure to the disinfectant plus washing in the reprocessor (appropriate length of time and temperature), results in an average $\log _{10}$ reduction in microorganisms (Mycobacterium terrae) of 8.2 to 12.2, depending on which endoscope surface was examined. Reprocessor cleaning alone resulted in a 3.4 to $4.6 \log _{10}$ reduction (this would be approximately $99.99 \%$ effective). No information was available concerning reduction in viruses for this reprocessor.

There were uncertainties regarding the effectiveness of the glutaraldehyde used because there was not evidence to show that it was tested for efficacy as required. Given this information and the uncertainties around the effectiveness of the glutaraldehyde used in the facility, risk estimates were calculated using the following two scenarios:

Scenario 1: Assume that the exposure to glutaraldehyde was completely ineffective and that any reduction in bioburden of microorganisms was obtained by washing alone; therefore efficacy of 'cleaning/ disinfection' was a $4 \log _{10}$ reduction $(99.99 \%)$

Scenario 2: Assume that the exposure to glutaraldehyde was effective for inactivating viruses and that the reduction in bioburden was $8 \log _{10}$ (99.999999\%).

\section{Estimates for scenario 1}

Endoscopy without biopsy:

- HIV $2.25 \times 10^{-11}$ to $2.25 \times 10^{-10}$

- HBV $4.6 \times 10^{-11}$ to $4.6 \times 10^{-9}$

- HCV between risks for HIV and HBV (no transmission risk available for mucosal exposure for HCV to create an estimate, but this approach agrees with the literature [20]) 
Endoscopy with biopsy:

- HIV $2.7 \times 10^{-11}$ to $2.7 \times 10^{-10}$

- HBV $1.2 \times 10^{-9}$ to $6 \times 10^{-7}$

- $\mathrm{HCV} 1.7 \times 10^{-9}$ to $1.7 \times 10^{-8}$

Estimates for Scenario 2

Endoscopy without biopsy:

- HIV $2.25 \times 10^{-14}$ to $2.25 \times 10^{-15}$

- HBV $4.6 \times 10^{-13}$ to $4.6 \times 10^{-11}$

- HCV between risks for HIV and HBV (see explanation above)

Endoscopy with biopsy:

- HIV $2.7 \times 10^{-14}$ to $2.7 \times 10^{-15}$

- HBV $1.2 \times 10^{-13}$ to $6 \times 10^{-11}$

- $\mathrm{HCV} 1.7 \times 10^{-12}$ to $1.7 \times 10^{-13}$

The highest risk estimate was for HBV when a biopsy took place and assumed that the glutaraldehyde being used was ineffective $6 \times 10^{-7}$ (6 in 10 million, 0.6 in 1 million).

\section{REFERENCES}

1. Canadian Association of Gastroenterology. Quality in gastroenterology. Canadian Association of Gastroenterology 2012. $<$ www.cag-acg.org/quality-program-endoscopy> (Accessed December 5, 2012).

2. Alharbi O, Rabeneck L, Paszat LF, et al. Factors associated with colonoscopy performed in nonhospital settings. Can J Gastroenterol 2010;24:419.

3. The College of Physicians and Surgeons of Ontario. Bridging the gap: A patient safety imperative. The Out-of-Hospital Premises Inspection Program Report. The College of Physicians and Surgeons of Ontario, 2012

4. Schembre DB. Infectious complications associated with gastrointestinal endoscopy. Gastrointest Endosc Clin N Am 2000;10:215.

5. Srinivasan A. Epidemiology and prevention of infections related to endoscopy. Curr Infect Dis Rep 2003;5:467-72.

6. Weber DJ, Rutala WA. The prevention of infection following gastrointestinal endoscopy: The importance of prophylaxis and reprocessing. In: Marino Jr AJ, ed. Gastrointestinal Diseases: An Endoscopic Approach. Thorofare: Slack Inc, 2002:87-106.

7. Holodniy M, Oda G, Schirmer PL, et al. Results from a large-scale epidemiologic look-back investigation of improperly reprocessed endoscopy equipment. Infect Control Hosp Epidemiol 2012;33:649.

8. Bronowicki JP, Venard V, Bott C, et al. Patient-to-patient transmission of hepatitis $\mathrm{C}$ virus during colonoscopy. N Engl J Med 1997;337:237-40.

9. Spach DH, Silverstein FE, Stamm WE. Transmission of infection by gastrointestinal endoscopy and bronchoscopy. Ann Intern Med 1993;118:117-28.

10. Bond W, Favero M, Petersen N, Gravelle C, Ebert J, Maynard J. Survival of hepatitis B virus after drying and storage for one week. Lancet 1981;317:550-1.

11. Ciesek S, Friesland M, Steinmann J, et al. How stable is the hepatitis $\mathrm{C}$ virus (HCV)? Environmental stability of $\mathrm{HCV}$ and its susceptibility to chemical biocides. J Infect Dis 2010;201:1859-66.

12. Doerrbecker J, Friesland M, Ciesek S, et al. Inactivation and survival of hepatitis C virus on inanimate surfaces. J Infect Dis 2011;204:1830-8.

13. Kamili S, Krawczynski K, McCaustland K, Li X, Alter MJ. Infectivity of hepatitis $C$ virus in plasma after drying and storing at room temperature. Infect Control Hosp Epidemiol 2007;28:519-24.

14. Paintsil E, Binka M, Patel A, Lindenbach BD, Heimer R. Hepatitis C virus maintains infectivity for weeks after drying on inanimate surfaces at room temperature: Implications for risks of transmission. J Infect Dis 2014;209:1205-11.

15. Bayoumi A, Strike C, Brandeau M, et al. Report of the Toronto and Ottawa Supervised Consumption Assessment Study. 2012. Toronto, Ontario, St. Michael's Hospital and the Dalla Lana School of Public Health, University of Toronto. <www.catie.ca/sites/default/files/ TOSCA\%20report\%202012.pdf> (Accessed May 1, 2013).

16. The College of Physicians and Surgeons of Ontario. Premises inspection committee report: Dr. C. Farazli MD, FRCP (C) Level 2. The College of Physicians and Surgeons of Ontario 2011 June 22; <www.cpso.on.ca/CPSO/CMSWebParts/OhpOutcomePdf. aspx?flash=true\&pdfid=190586> (Accessed September 1, 2014).

\section{Limitations}

These risk estimates are subject to several limitations. The assessment was based on observations regarding practices noted during one inspection. The efficacy of the enzymatic detergent and the efficacy of manual cleaning were not included in the calculations because the detergent being used was expired. There is scientific literature to suggest that cleaning in reprocessors is equivalent to manual cleaning; however, given the inspector's observations the effect of manual cleaning was not included in these estimates to create a 'worst-case' scenario, which may have resulted in an overestimation of disease transmission risk. There are uncertainties concerning the effectiveness of the glutaraldehyde that was being used and what this would generally be at this facility; there was no additional information provided to refine the estimate. The efficacy of cleaning of viruses by the reprocessor used in the facility was based on extrapolated data from cleaning of bacteria in this reprocessor.

17. Remis RS, Swantee C, Liu J. Report on HIV/AIDS in Ontario 2008. Ontario HIV Epidemiologic Monitoring Unit 2010. <www. ohemu.utoronto.ca/doc/2011/PHERO2008_report_final_rev_ Sept2010.pdf $>$ (Accessed December 5, 2012).

18. Remis RS. The epidemiology of hepatitis C infection in Ontario, 2004. Ontario HIV Epidemiologic Monitoring Unit 2007; <www.ohemu. utoronto.ca/doc/EpiHCVOnt.pdf> (Accessed December 5, 2012).

19. Sherman M, Shafran S, Burak K, et al. Management of chronic hepatitis B: Consensus guidelines. Can J Gastroenterol 2007;21(Suppl C):5C.

20. Rutala WA, Weber DJ. How to assess risk of disease transmission to patients when there is a failure to follow recommended disinfection and sterilization guidelines. Infect Control Hosp Epidemiol 2007;28:146-55.

21. Public Health Agency of Canada. Infection Prevention and Control Guideline for Flexible Gastrointestinal Endoscopy and Flexible Bronchoscopy. 2011.

22. Maher M. Issue analysis: Community infection prevention and control breach. Ottawa: Ottawa Public Health; November 17, 2011.

23. Disclosure Working Group. Canadian disclosure guidelines. Edmonton: Canadian Patient Safety Institute, 2008.

24. Canadian Medical Protective Association. Communicating with your patient about harm: Disclosure of adverse events. 2008.

25. Beauchamp TL, Childress JF. Principles of biomedical ethics, 5th edn. Oxford University Press, USA; 2001.

26. University of Toronto Joint Centre for Biothics Pandemic Influenza Working Group. Stand on guard for thee: Ethical considerations in preparedness planning for pandemic influenza. Toronto: University of Toronto, Joint Centre for Bioethics, 2005.

27. Dudzinski DM, Hebert PC, Foglia MB, Gallagher TH. The disclosure dilemma - large-scale adverse events. N Engl J Med 2010;363:978-86.

28. Upshur RE. Principles for the justification of public health intervention. Can J Publ Health 2002;93:101.

29. Osiowy C. Sensitive detection of HBsAg mutants by a gap ligase chain reaction assay. J Clin Microbiol 2002;40:2566-71.

30. Minuk GY, Kowalec K, Caouette S, Larke B, Osiowy C. The prevalence and long term outcome of occult hepatitis B virus infections in community based populations. J Med Virol 2012;84:1369-75

31. Osiowy C, Andonov A, Borland J, Huynh C, Uhanova J, Minuk G. HBV DNA diagnostic testing: Positivity is in the eye of the beholder (Abstract 1033). Hepatology 2013;58(S1):706A.

32. Raimondo G, Allain J, Brunetto M, et al. Statements from the Taormina expert meeting on occult hepatitis $\mathrm{B}$ virus infection. J Hepatol 2008;49:652-7.

33. Tamura K, Peterson D, Peterson N, Stecher G, Nei M, Kumar S. MEGA5: Molecular evolutionary genetics analysis using maximum likelihood, evolutionary distance, and maximum parsimony methods. Mol Biol Evol 2011;28:2731-9.

34. Wu J, Wu HX, Andonov A, et al. Epidemiological profile of newly diagnosed patients with hepatitis $C$ infection in 6 health regions across Canada over an 8-year period. Ann Epidemiol 2007;17:740-1.

35. Boulos D, Goedhuis NJ, Wu J, et al. Enhanced surveillance for acute and likely acute hepatitis B in Canada: 1999 to 2002. Can J Infect Dis Med Microbiol 2005;16:275. 
36. Wu HX, Wu J, Wong T, et al. Enhanced surveillance of newly acquired hepatitis C virus infection in Canada, 1998 to 2004. Scand J Infect Dis 2006;38:482-9.

37. Ontario Agency for Health Protection and Promotion (Public Health Ontario). Provincial Infectious Diseases Advisory Committee. Best practices for cleaning, disinfection and sterilization of medical equipment/devices. 3rd edn. May 2013. Toronto: Queen's Printer for Ontario. <www.publichealthontario.ca/en/eRepository/PIDAC_ Cleaning_Disinfection_and_Sterilization_2013.pdf $>$ (Accessed November 21, 2014).

38. Statistics Canada. Ontario (Code 35). Census Profile. 2011 Census. Statistics Canada Catalogue no.98-316-XWE . Ottawa: Statistics Canada, 2012.

39. Johnson IL. An outbreak of hepatitis B associated with reusable subdermal electroencephalogram electrodes. CMAJ 2000;162:1127-31.

40. Patel P, Srinivasan A, Perz J. Developing a broader approach to management of infection control breaches in health care settings. Am J Infect Control 2008;36:685-90.
41. Public Health Policy and Programs Branch, Public Health Division, Ministry of Health and Long-Term Care. Report to the Chief Medical Officer of Health from the Community Infection Prevention and Control Lapses Task Group. 2014.

42. Centers for Disease Control and Prevention. 2001. Updates U.S. Public Health Service Guidelines for the Management of Occupational Exposures to HBV, HCV, and HIV and Recommendations for Postexposure Prophylaxis. MMWR 50 (No. RR-11).

43. Morris J, Duckworth GJ, Ridgway GL. Gastrointestinal endoscopy decontamination failure and the risk of transmission of blood-borne viruses: A review. J Hosp Infect 2006;63:1-13.

44. Custom Ultrasonics, 2007. Summary and Overview. Inc. System 83 PlusTM Washer-Disinfector. <www.customultrasonics.com/images/ cart_files/83plus2booklet.pdf> (Accessed September 9, 2011). 


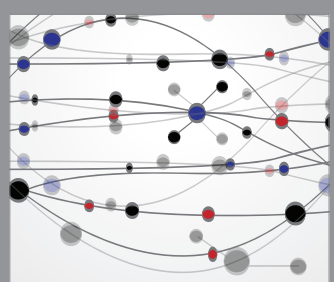

The Scientific World Journal
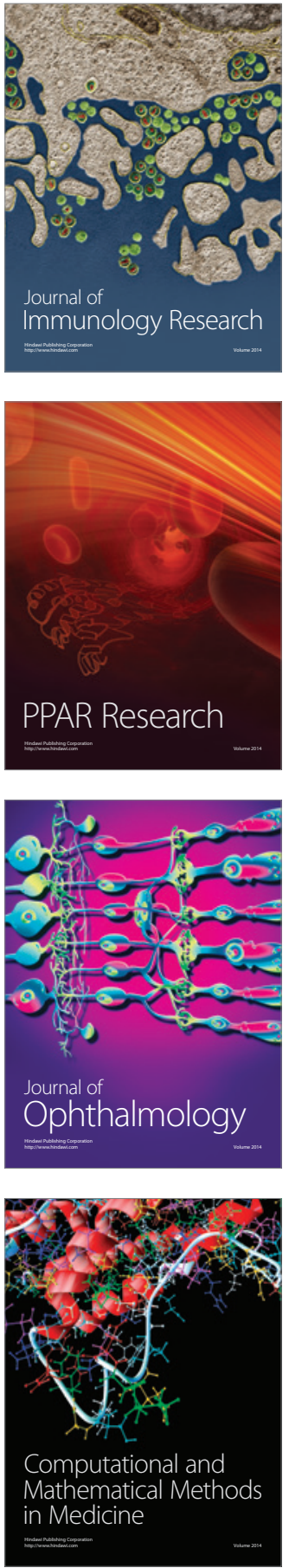

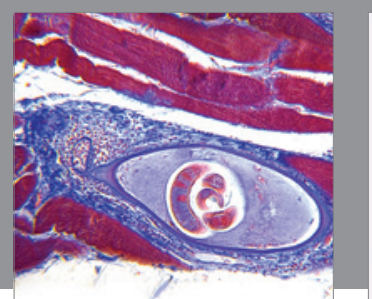

Gastroenterology Research and Practice

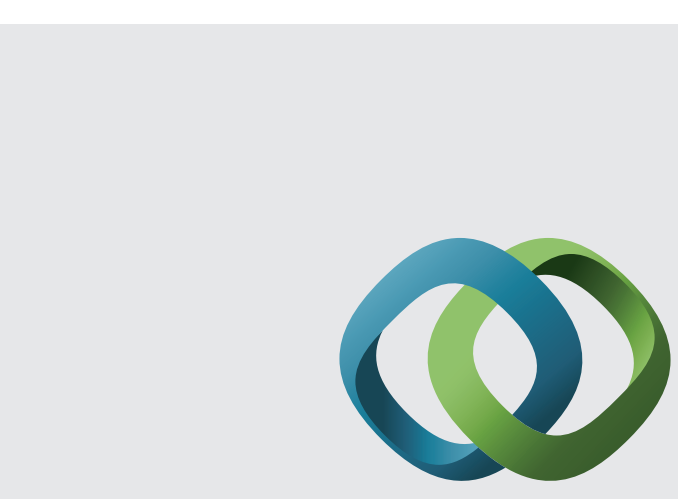

\section{Hindawi}

Submit your manuscripts at

http://www.hindawi.com
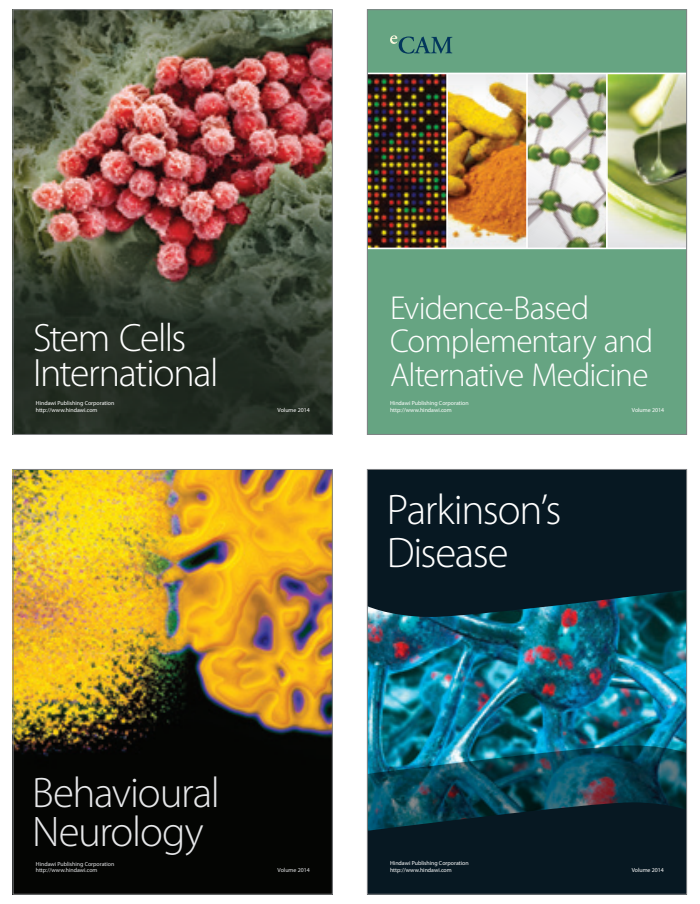
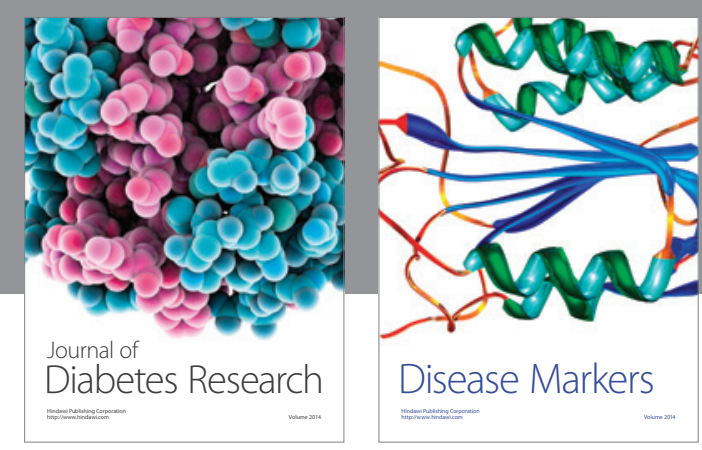

Disease Markers
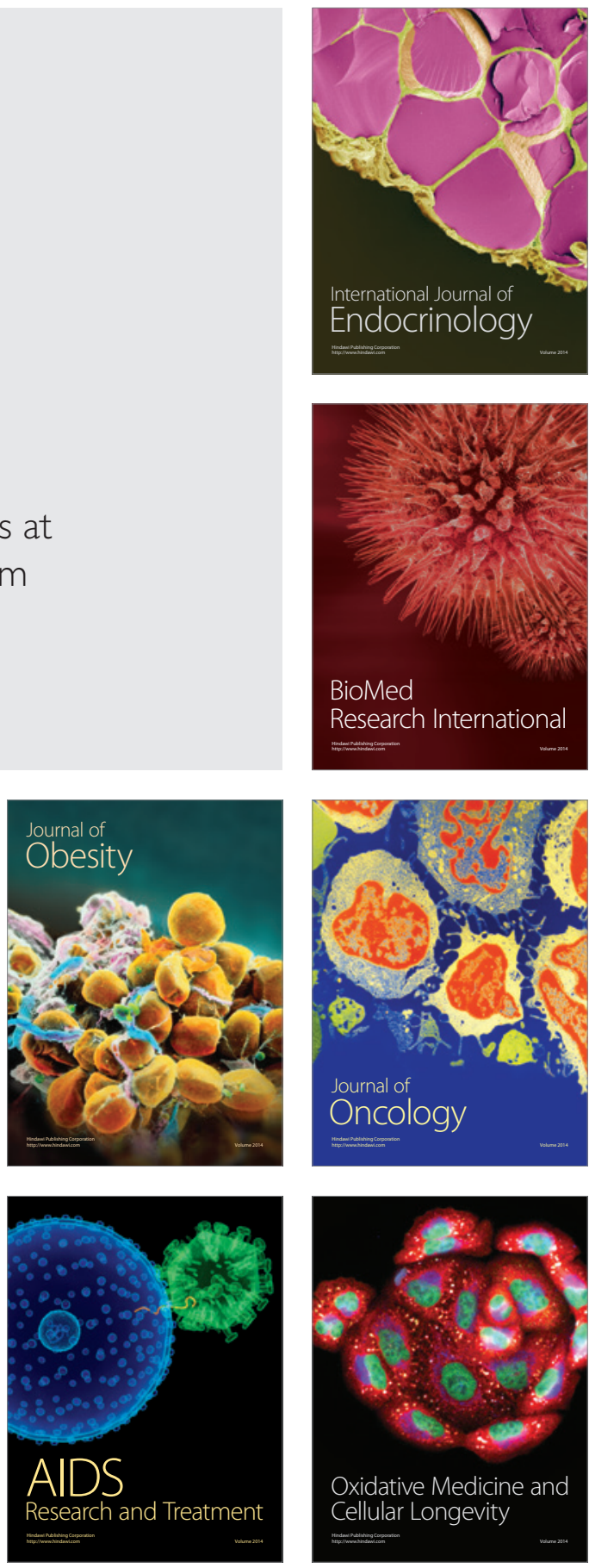